\title{
Pulmonary arterial hypertension preceding idiopathic pulmonary fibrosis in a BMPR2 mutation positive patient
}

\section{To the Editor:}

When pulmonary hypertension (PH) develops in a patient with idiopathic pulmonary fibrosis (IPF) it is usually categorised in World Health Organization (WHO) group III: PH associated with chronic lung disease and/or hypoxia [1]. Given the fact that pulmonary arterial hypertension (PAH) (WHO group I) and IPF are both rare and fatal diseases, their manifestation in a single patient is unlikely to occur by chance. Here, we describe for the first time the concurrent development of IPF and $\mathrm{PH}$ in a patient with a bone morphogenetic protein receptor type 2 (BMPR2) mutation.

An 80-year-old female presented with fever, chills, shortness of breath, chest pain and a decline in exercise tolerance. She had been diagnosed 3 years before with hereditary PAH (HPAH) associated with a BMPR2 mutation (c.637C>T; p.Arg213X (reference sequence NM_001204)), for which she received ambrisentan, sildenafil and diuretic treatment. Right heart catheterisation at the time of HPAH diagnosis had shown a mean pulmonary artery pressure of $42 \mathrm{mmHg}$ and a pulmonary arterial wedge pressure of $2 \mathrm{mmHg}$. Pulmonary function tests had shown a vital capacity of $2.7 \mathrm{~L}(139 \%)$ and a forced expiratory volume in $1 \mathrm{~s}$ of $2.3 \mathrm{~L}(144 \%)$. She was a former smoker and denied the use of alcohol or drugs. Her mother had died at the age of 36 years from an unknown cause and her granddaughter had also been diagnosed with HPAH. On physical examination the patient appeared cyanotic, cachectic and dyspnoeic. Her respiratory rate was 15 breaths per minute and pulse oximetry showed a saturation of $95 \%$, with $4 \mathrm{~L}$ of oxygen per minute, and $85 \%$ in atmospheric air. Her heart rate was 90 beats per minute, temperature was $38^{\circ} \mathrm{C}$ and blood pressure was 100/60 mmHg. There was no jugular vein distension. On lung auscultation she had basal coarse crackles in both lungs. Blood biochemistry showed hyperglycaemia $\left(15.0 \mathrm{mmol} \cdot \mathrm{L}^{-1}\right)$, elevated erythrocyte sedimentation rate $\left(79 \mathrm{~mm} \cdot \mathrm{h}^{-1}\right)$, leukocytosis $\left(13 \times 10^{9} \cdot \mathrm{L}^{-1}\right)$, and hyponatraemia $\left(130 \mathrm{mmol} \cdot \mathrm{L}^{-1}\right)$, while her creatinine was normal. Chest radiography showed reticular opacities in the periphery of both lungs. Chest computed tomography (CT) showed an extensive and diffuse fibrotic opacification in both lungs with a peripheral and basal distribution, a honeycomb pattern and diffuse traction bronchiectasis, all consistent with a diagnosis of IPF (fig. 1). On review, a chest CT scan from 3 years earlier showed paraseptal thickening and a minimal presence of subpleural ground-glass opacities (fig. 1). At the time of diagnosis, these abnormalities were not considered of clinical importance. Moreover, the presence of a BMPR2 mutation, together with a positive family history, had rendered a diagnosis of HPAH much more likely.

We describe for the first time a patient with an exceptional concurrent presence of HPAH and IPF. The prevalence of IPF is between 14.0 and 42.7 per million persons depending on the definition [2], and the prevalence of $B M P R 2$ mutation positive $\mathrm{PAH}$ is $\sim 1.5$ per million individuals [1]. The likelihood that these rare and fatal disorders manifest in one person is negligible, favouring the hypothesis that both diagnoses in this patient were somehow related. The combination of the two diseases in a single patient has never been described. This may be due to the fact that BMPR2 mutation positive idiopathic PAH patients are diagnosed at a younger age (mean age 45 years) than IPF patients (mean age 66 years) [3] and that the reduced life expectancy prevents PAH patients from developing IPF. The patient described here was initially diagnosed with BMPR2 mutation positive PAH. In a case where IPF preceded the development of PAH, the presence of $\mathrm{PH}$ would be classified as $\mathrm{PH}$ secondary to pulmonary disease. For this reason, the real prevalence of the combination of PAH and IPF is unknown. This begs the question whether BMPR2 mutations might underlie PH in some of the IPF patients and whether similar pathways might lead to two different diseases.

Whether the exact site of the mutation in the BMPR2 gene in this patient was important for the combined development of IPF and PAH remains to be determined. Another relevant research question in this respect would be to determine whether polymorphisms of PAH-related genes (BMPR2, ALK1, etc.) exist in the population of patients with both IPF and PH.

Recent publications have shown that the bone morphogenetic protein antagonist gremlin is of interest in the pathogenesis of PAH and IPF [4-8]. In IPF, transforming growth factor- $\beta$ activation and increased gremlin expression are associated with impaired bone morphogenetic protein signalling, resulting in 

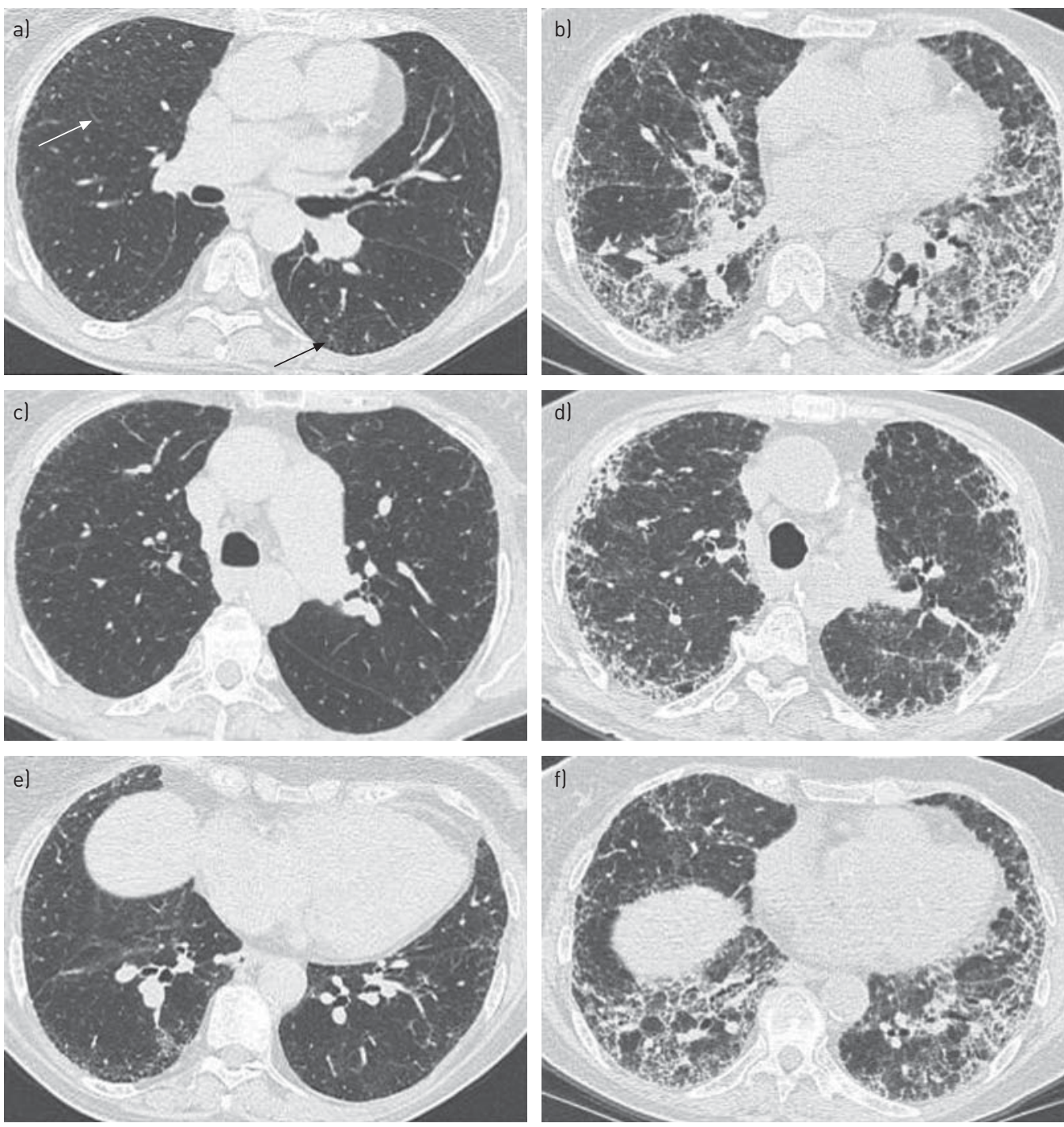

FIGURE 1 a) Chest computed tomography (CT) scan from 2009 showing paraseptal thickening (white arrow) and a minimal presence of subplureal ground-glass opacities (black arrow). b) Chest CT scan from 2013 showing extensive and diffuse fibrotic opacification in both lungs with a peripheral and basal distribution, a honeycomb pattern and diffuse traction bronchiectasis. c) Cranial slide chest CT scan from 2009. d) Cranial slide chest CT scan from 2013. e) Caudal slide chest CT scan from 2009. f) Caudal slide chest CT scan from 2013.

proliferation of myofibroblasts and fibroblasts. HPAH patients with BMPR2 gene mutations develop PAH due to a lack of functional BMPR2, which is associated with proliferation and resistance to apoptosis of pulmonary artery smooth muscle cells [1]. Most mutations of the BMPR2 gene lead to haploinsufficiency and the penetrance is highly variable. It has been suggested that a "second hit" is required to precipitate the phenotype and could cause further deregulation of BMPR2/Smad signalling, leading to PAH [9, 10]. Although the significance of gremlin levels in $\mathrm{PAH}$ has yet to be determined, in a mutation carrier developing IPF, hypoxia or increased gremlin levels may account for a second insult, leading to the manifestation of PAH.

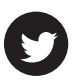

@ERSpublications

Concurrent pulmonary hypertension and pulmonary fibrosis in a bone morphogenetic protein receptor type 2 mutation carrier http://ow.ly/qeG2Z

Aniek J. Raamsteeboers, Harm Jan Bogaard and Anton Vonk Noordegraaf

Dept of Pulmonary Medicine and Institute for Cardiovascular Medicine, VU University Medical Center, Amsterdam, The Netherlands. 
Correspondence: A. Vonk Noordegraaf, Dept of Pulmonary Medicine, VU University Medical Center, De Boelelaan 1117, 1081 HV Amsterdam, The Netherlands. E-mail: a.vonk@vumc.nl

Received: Aug 192013 | Accepted after revision: Sept 152013

Support statement: A. Vonk Noordegraaf was supported by the Netherlands Organisation for Scientific Research-VIDI grant (project number 917.96.306).

Conflict of interest: Disclosures can be found alongside the online version of this article at err.ersjournals.com

Provenance: Submitted article, peer reviewed.

\section{References}

1 McLaughlin VV, Archer SL, Badesch DB, et al. ACCF/AHA 2009 expert consensus document on pulmonary hypertension a report of the American College of Cardiology Foundation Task Force on Expert Consensus Documents and the American Heart Association developed in collaboration with the American College of Chest Physicians, American Thoracic Society, Inc. and the Pulmonary Hypertension Association. J Am Coll Cardiol 2009; 53: $1573-1619$.

2 Raghu G. Idiopathic pulmonary fibrosis: guidelines for diagnosis and clinical management have advanced from consensus-based in 2000 to evidence-based in 2011. Eur Respir J 2011; 37: 743-746.

3 Wells AU. Managing diagnostic procedures in idiopathic pulmonary fibrosis. Eur Respir Rev 2013; 22: 158-162.

4 Cahill E, Costello CM, Rowan SC, et al. Gremlin plays a key role in the pathogenesis of pulmonary hypertension. Circulation 2012; 125: 920-930.

5 Costello CM, Howell K, Cahill E, et al. Lung-selective gene responses to alveolar hypoxia: potential role for the bone morphogenetic antagonist gremlin in pulmonary hypertension. Am J Physiol Lung Cell Mol Physiol 2008; 295: L272-L284.

6 Myllärniemi M, Lindholm P, Ryynänen MJ, et al. Gremlin-mediated decrease in bone morphogenetic protein signaling promotes pulmonary fibrosis. Am J Respir Crit Care Med 2008; 177: 321-329.

7 Koli K, Myllärniemi M, Vuorinen K, et al. Bone morphogenetic protein-4 inhibitor gremlin is overexpressed in idiopathic pulmonary fibrosis. Am J Pathol 2006; 169: 61-71.

8 Myllärniemi M, Vuorinen K, Pulkkinen V, et al. Gremlin localization and expression levels partially differentiate idiopathic interstitial pneumonia severity and subtype. J Pathol 2008; 214: 456-463.

9 Durrington HJ, Morrell NW. What we know and what we would like to know about genetics and pulmonary arterial hypertension. Int J Clin Pract Suppl 2009; 161: 11-16.

10 Costello CM, Cahill E, Martin F, et al. Role of gremlin in the lung: development and disease. Am J Respir Cell Mol Biol 2010; 42: 517-523.

Eur Respir Rev 2014; 23: 147-149 | DOI: 10.1183/09059180.00005513 | Copyright @eERS 2014 ERR articles are open access and distributed under the terms of the Creative Commons Attribution Non-Commercial Licence 3.0. 